\title{
Corticosterone Modulates Auditory Gating in Mouse
}

\author{
Christina R Maxwell', Richard S Ehrlichman', Yuling Liang', David R Gettes², Dwight L Evans², \\ Stephen J Kanes', Ted Abel ${ }^{3}$, Jonathan Karp ${ }^{4}$ and Steven J Siegel ${ }^{*, I}$ \\ 'Division of Neuropsychiatry, Department of Psychiatry, University of Pennsylvania, Philadelphia, PA, USA; ${ }^{2}$ Department of Psychiatry, University \\ of Pennsylvania, Philadelphia, PA, USA; ${ }^{3}$ Department of Biology, University of Pennsylvania, Philadelphia, PA, USA; ${ }^{4}$ Department of Biology, \\ Rider University, Lawrenceville, NJ, USA
}

\begin{abstract}
Previous studies suggest that circulating glucocorticoids may influence the encoding and processing of sensory stimuli. The current study investigated this hypothesis by measuring the generation (amplitude), gating (recovery cycle), and sensitivity (intensity function) of auditory evoked responses in C57BL/6 mice treated with chronic corticosterone (0, 1, 5, 15 , or $30 \mathrm{mg} / \mathrm{kg} /$ day for 14 days). We found that low-dose corticosterone ( 5 but not I mg/kg/day) enhanced the amplitude and improved gating of evoked potentials without affecting the intensity function. In comparison, higher doses ( 15 and $30 \mathrm{mg} / \mathrm{kg} /$ day) decreased the amplitude and impaired gating of evoked potentials, also without altering the stimulus intensity function. At all doses, lower amplitudes of evoked potentials were significantly correlated with higher circulating corticosterone levels. These data highlight the need to consider serum glucocorticoid levels when assessing human disease states associated with aberrations of information processing such as schizophrenia and depression. Neuropsychopharmacology (2006) 3 I, 897-903. doi: I 0.1038/sj.npp. I 300879; published online 24 August 2005
\end{abstract}

Keywords: auditory-evoked potentials; mouse; corticosterone; N40; interstimulus interval; stimulus intensity response

\section{INTRODUCTION}

An auditory stimulus elicits a well-characterized progression of neural activity within the auditory system from the cochlea through the primary auditory cortex and subsequent association areas. Sequential components of human auditory evoked potentials (AEPs) that are commonly studied include the P50 (positive component at $50 \mathrm{~ms}$ or P1 for position), N100 (N1), P200 (P2), and P300 (P3). Rodents display a P20 (P1), N40 (N1), P80 (P2), and P120 (P3) topography that is similar to the corresponding P1, N1, P2, and P3 human components (Ehlers and Somes, 2002; Maxwell et al, 2004b; Siegel et al, 2003; Umbricht et al, 2004). As such, these characteristics of signal transduction through the auditory pathways are conserved across species (Adler et al, 1986; Javitt et al, 2000; Maxwell et al, 2004b; Pincze et al, 2001).

Cross-species similarities in the topography and response properties of AEPs has allowed for the use of rodent models to assess the potential effects of physiologic, pharmacologic, and genetic alterations on human AEPs (Adler et al, 1986; Knight et al, 1985). In such models, AEPs represent neuronal activity in response to controlled stimuli. Modi-

\footnotetext{
*Correspondence: Dr SJ Siegel, Department of Psychiatry, University of Pennsylvania, Clinical Research Building, Rm 145a, 4 I 5 Curie Boulevard, Philadelphia, PA 19104, USA. Tel: + I 215573 0278, Fax: + I 215573 204I,E-mail: siegels@mail.med.upenn.edu

Received 20 April 2005; revised 16 June 2005; accepted 7 July 2005 Online publication: 21 July 2005 at http://www.acnp.org/citations/ Npp072 105050260/default.pdf
}

fication of stimulus characteristics including intensity and interstimulus interval (ISI) results in predictable AEP responses, facilitating the ability to correlate specific components across species. For example, increases in stimulus intensity produce increased amplitude of evoked responses, which is thought to reflect a measure of auditory sensitivity (Halford, 2003; Hegerl et al, 2001). Similarly, reducing the ISI leads to a reduction in amplitude, demonstrating the ability to filter or gate repetitive incoming stimuli. In humans, the normal ISI response is a linear increase in N1 amplitude between 0.25 and $8 \mathrm{~s}$ ISI (Budd et al, 1998; Shelley et al, 1999). However, the N1 amplitude does not increase in response to longer ISI in patients with schizophrenia (Shelley et al, 1999). Thus, a rodent model that recreates similar impairments in the normal ISI response properties of the mouse $\mathrm{N} 1$ has been used to examine factors that may contribute to sensory processing abnormalities in schizophrenia (Adler et al, 1986; Light and Braff, 1999; Maxwell et al, 2004a).

Pharmacological treatments that reduce the amplitude of evoked components are used to model deficits in the ability to encode auditory information whereas treatments that produce larger than normal responses indicate potential enhancements in auditory processing (Adler et al, 1986; Light and Braff, 1999; Maxwell et al, 2004a). For example, amphetamine-induced reductions in the amplitude and gating of the P1 and N1 AEPs in humans and animals are postulated as predictive models of sensory processing impairments in schizophrenia (Adler et al, 1986; Janowsky and Risch, 1979; Light and Braff, 1999). Interestingly, 
corticosteroid administration has been suggested to model schizophrenia-like sensory processing impairments (Stevens et al, 2001).

A limited number of studies evaluate the effects of corticosteroid treatment on sensory processing and behavioral neurobiology in humans. Acute and subchronic administration of hydrocortisone transiently enhanced amplitude of AEPs in normal subjects (Ashton et al, 2000; Born et al, 1989). However, repeated corticosteroid administration impaired performance on memory tasks, suggesting that behavioral outcomes may be dependent on the dose or length of corticosteroid exposure and perhaps homeostatic modulation of endogenous systems that result from exogenous administration (McAllister-Williams and Rugg, 2002).

Administration of exogenous corticosterone has been shown to cause impairments in gating of the $\mathrm{P} 1-\mathrm{N} 1$ complex in adrenalectomized mice, which has been proposed to model schizophrenia-like AEP deficits (Stevens et al, 2001). However, previous work has utilized a single stimulus intensity and ISI, which does not allow for evaluation of steroid influences on specific psychometric parameters that modulate the amplitude of evoked components. We address this gap in the literature by examining AEP responses in mice at three stimulus intensities, four ISI, and five levels of corticosterone treatment. The current study evaluates chronic corticosterone treatment in mice with intact adrenals, controlling for the length of exposure and allowing all forms of normal adaptation to occur. Our goal is to investigate influences of circulating corticosterone on the response properties of the auditory system using ISI and stimulus intensity functions. We believe these findings will have important implications for psychiatric disorders like schizophrenia and depression where alterations in cortisol regulation may influence sensory processing.

\section{METHODS}

\section{Animals}

C57BL/6J male mice $(n=44)$ were obtained at 8 weeks of age from Jackson Laboratories (Bar Harbor, ME). All testing was conducted between 10 and 11 weeks of age. We have previously shown that the N40 component of AEP in C57BL/6J mice increases in amplitude with lengthening ISI, similar to the human N1 (Maxwell et al, 2004b; Shelley et al, 1999). Additionally, this strain is responsive to a variety of compounds that reduce N40 amplitude (NMDA antagonists and stimulants) as well as enhance N40 amplitude (antipsychotics and phosphodiesterase inhibitors) (Connolly et al, 2004; Liang et al, 2004; Maxwell et al, 2004a, b; Siegel et al, 2003). Previous reports have characterized this strain using a variety of auditory assessments including the auditory brainstem response to verify hearing at 3 months of age (Siegel et al, 2005; Zheng et al, 1999). We also use a low-frequency $1500 \mathrm{~Hz}$ tone to avoid confounds related to age-related (5-6 months) high-frequency $(>20 \mathrm{kHz})$ hearing loss (Ehlers and Somes, 2002; Erway et al, 1993; Willott and Carlson, 1995). Therefore, we believe that C57BL/6J mice are an appropriate strain for the current investigation, based on previous psychometric and pharmacological findings.

\section{Treatment Groups}

The study followed a between-subjects design in which groups were administered either corticosterone $1 \mathrm{mg} / \mathrm{kg} /$ day $(n=8), 5 \mathrm{mg} / \mathrm{kg} /$ day $(n=9), 15 \mathrm{mg} / \mathrm{kg} /$ day $(n=9), 30 \mathrm{mg} /$ $\mathrm{kg} /$ day $(n=9)$, or vehicle $(n=9)$ (Sigma Aldrich, St Louis, $\mathrm{MO}$ ). Vehicle (PEG 400), 1 , and $5 \mathrm{mg} / \mathrm{kg} /$ day were delivered via subcutaneous Alzet micro-osmotic pumps (Durect Corp. Model 1002, Cupertino, CA) for 14 days. Since the maximum dose released in pumps is $5 \mathrm{mg} / \mathrm{kg} /$ day, the doses of 15 and $30 \mathrm{mg} / \mathrm{kg} /$ day corticosterone were delivered through subcutaneous pellets (40\% corticosterone, 50:50 poly-lactide-co-glycolide) implanted 14 days prior to testing. In vitro and in vivo corticosterone release from Alzet osmotic pumps was previously characterized (DeKrey and Kerkvliet, 1995; Man et al, 2002). Corticosterone release from pellets was determined prior to implantation using previously published protocols (Siegel et al, 2002). Corticosterone administration whether by osmotic pump or subcutaneous pellet began 7 days prior to electrode implantation described below. All protocols were conducted in accordance with the University of Pennsylvania Laboratory Animal Resources guidelines and were approved by the Institutional Animal Care and Use Committee. All efforts were made to minimize animal number and suffering.

\section{Surgery}

Animals underwent stereotaxic implantation of tripolar electrode assemblies (PlasticsOne Inc., Roanoke, VA) 7 days prior to nonanesthetized recording of AEPs as previously published (Connolly et al, 2004, 2003; Maxwell et al, 2004a,b; Siegel et al, 2003). All animals were anesthetized with ketamine/xylazine $(100 / 10 \mathrm{mg} / \mathrm{kg})$ for implantation of electrodes. The electrode surgical procedure consisted of a unipolar recording electrode placed in the CA3 region of hippocampus, referenced to the ipsilateral frontal sinus using the stereotaxic coordinate system (recording electrode: $1.4 \mathrm{~mm}$ posterior, $2.65 \mathrm{~mm}$ lateral, and $2.75 \mathrm{~mm}$ deep relative to bregma; reference electrode: $0.6 \mathrm{~mm}$ anterior, $2.65 \mathrm{~mm}$ lateral, and $0.75 \mathrm{~mm}$ deep relative to bregma). Unlike our previous report using bipolar electrodes to isolate hippocampal activity during seizures, the current procedure produces a difference vector that reflects whole brain electrical activity to more accurately model human scalp electroencephalogram recordings (Frankel et al, 2005). Electrode placement was verified to be in the target region using Perls iron reaction (LaBossiere and Glickstein, 1976).

\section{AEPs and Corticosterone}

Recording of evoked potentials was performed 7 days after implantation of electrodes, which corresponded to 14 days of drug exposure. Auditory stimuli were generated by Micro1401 hardware and Spike 5 software (Cambridge Electronic Design, Cambridge, UK) and were delivered through speakers attached to the cage top. Blocks of 80 of stimuli $(1500 \mathrm{~Hz}, 10 \mathrm{~ms}$ duration) were delivered at $0.25,0.5$, 4 , and $8 \mathrm{~s}$ ISI at 80,85 , and $90 \mathrm{db}$ ( $70 \mathrm{db}$ background) to produce steady-state measures of auditory recovery cycle (gating) (Erwin et al, 1994; Maxwell et al, 2004b). Wave- 
forms were sampled at $1667 \mathrm{~Hz}$, filtered between 1 and $500 \mathrm{~Hz}$, baseline corrected at stimulus onset and individual sweeps were rejected for movement artifact based on a criteria of two times the root mean squared amplitude per mouse. Average waves were created from $50 \mathrm{~ms}$ prestimulus to $200 \mathrm{~ms}$ poststimulus (Figure 1). Although the recording systems allows for acquisition and analysis of many components of the mouse AEP (N15, P20, N40, P80, and P120), we limited this initial study to the mouse N40 in due to the complexity introduced by analysis of four ISIs, three stimulus intensities, and five drug conditions for each component (Table 1). Mice were tested in their home cages

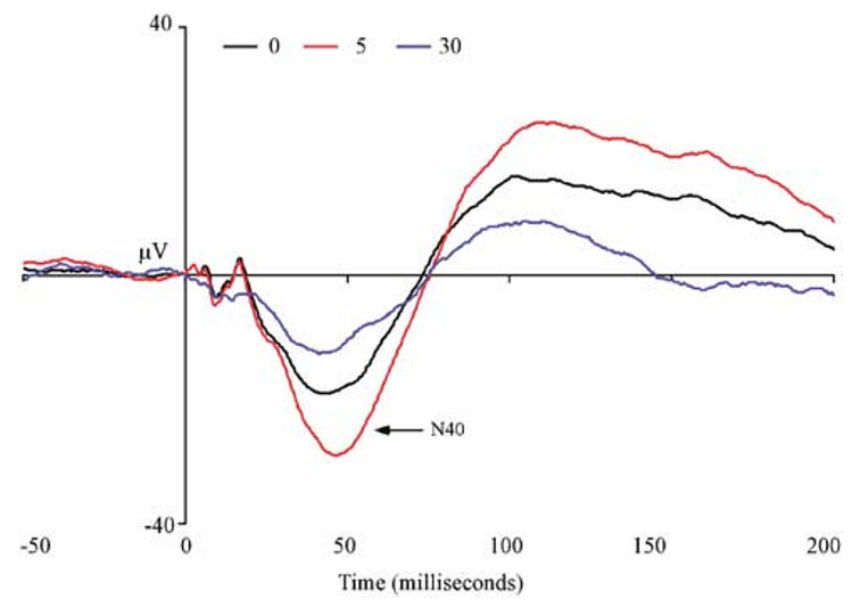

Figure I Grand average waveform $(\mu \vee)$ for vehicle and corticosterone (5 and $30 \mathrm{mg} / \mathrm{kg} /$ day) collapsed across stimulus intensity and $|S|$. Intermediate doses of $\mathrm{I}$ and $15 \mathrm{mg} / \mathrm{kg} /$ day were removed for clarity; $1 \mathrm{mg} / \mathrm{kg} /$ day waveform is similar to vehicle and $15 \mathrm{mg} / \mathrm{kg} /$ day is similar to $30 \mathrm{mg} / \mathrm{kg} /$ day. The location of the N40 is noted with an arrow.

Table I Mean, SEM, and Effect Size for the Significant Main Effects of Drug Condition, Stimulus Intensity, and ISI

\begin{tabular}{lcccc}
\hline & Variable & Mean & SEM & Effect size \\
\hline Drug condition & 0 & 26.34155 & 7.61581 & - \\
& 1 & 27.45587 & 7.119301 & 0.048772436 \\
& 5 & 36.86606 & 9.698892 & 0.460643241 \\
& 15 & 23.66492 & 8.72836 & -0.117152004 \\
& 30 & 21.26135 & 6.673969 & -0.222353224 \\
Stimulus intensity & 80 & 23.04436 & 3.623005 & - \\
& 85 & 27.65085 & 3.489772 & 0.191678973 \\
& 90 & 30.65863 & 4.725413 & 0.316834866 \\
Interstimulus interval & 0.25 & 19.97235 & 3.231689 & -0.559819329 \\
& 0.5 & 20.90296 & 3.377342 & -0.528579968 \\
& 4 & 30.94743 & 3.800491 & -0.191397362 \\
& 8 & 36.64905 & 4.490925 & -
\end{tabular}

-: the effect size for the main effect of drug is relative to the vehicle animals; main effect of intensity is relative to the $80 \mathrm{~dB}$ condition; main effects of ISI are relative to the $8 \mathrm{~s}$ stimuli. and allowed $15 \mathrm{~min}$ to acclimate to the testing apparatus prior to stimulus onset.

Normal auditory gating was defined as a significant reduction in amplitude at short intervals ( 0.25 and $0.5 \mathrm{~s}$ ISI) relative to longer intervals ( 4 and $8 \mathrm{~s}$ ) such that impaired gating implies little or no relative reduction in amplitude and enhanced gating reflects a larger reduction either by increases in amplitude at long intervals or further decreases at short intervals (Maxwell et al, 2004b). A significant interaction between drug condition and ISI would indicate corticosterone-induced changes in gating.

\section{Statistics}

The N40 component of the mouse AEP was defined as the most negative deflection between 25 and $60 \mathrm{~ms}$ after stimulus onset. The N40 amplitude was analyzed using repeated measures ANOVA to evaluate main effects of corticosterone, stimulus intensity, and ISI. Corticosterone was designated as the independent variable, stimulus intensity, and ISI were the repeated measures, and N40 amplitude was the dependent variable. Significant interactions between corticosterone and stimulus intensity; corticosterone and ISI; and corticosterone, intensity, and ISI were followed by Fisher LSD post hoc analyses. A $p$-value of less than 0.05 was considered a statistically significant finding. Effect sizes are provided for significant main effects and relevant interactions (Glass et al, 1981).

\section{Serum Corticosterone}

Animals were decapitated immediately following AEP testing (1500-1600 h). Trunk blood was harvested and serum collected for corticosterone analyses. Serum was assayed for free corticosterone using an Immuchem Double Antibody Corticosterone RIA kit (MP Biomedicals, LLC formerly ICN Orangeburg, NY). Serum samples from five of the mice tested in the AEP portion of the study were lost and not available for the corticosterone analysis due to human error. Therefore, the number of mice in each treatment group was vehicle $(n=8), 1 \mathrm{mg} / \mathrm{kg} /$ day corticosterone $(n=8), 5 \mathrm{mg} / \mathrm{kg} / \mathrm{day}(n=8), 15 \mathrm{mg} / \mathrm{kg} /$ day $(n=8)$, and $30 \mathrm{mg} / \mathrm{kg} /$ day $(n=7)$. Interassay and intrassay measures of variability for these assays were 5.08 and $6.97 \%$, respectively, which is consistent with the manufacturer's values of 7.2 and $7.1 \%$. Serum concentrations were determined from a software generated standard curve and reported in $\mathrm{ng} / \mathrm{ml}$. Resulting values were analyzed using general linear models ANOVA.

\section{Correlation}

A correlation between serum corticosterone concentration and N40 amplitude was evaluated using a Pearson's product/moment correlation analysis. In order to determine at which ISI the N40 amplitude is most closely correlated with changes in corticosterone serum levels, we performed correlations with serum corticosterone levels and each of the four ISI $(0.25,0.5,4$, and $8 \mathrm{~s})$ at the $90 \mathrm{~dB}$ stimulus intensity. 


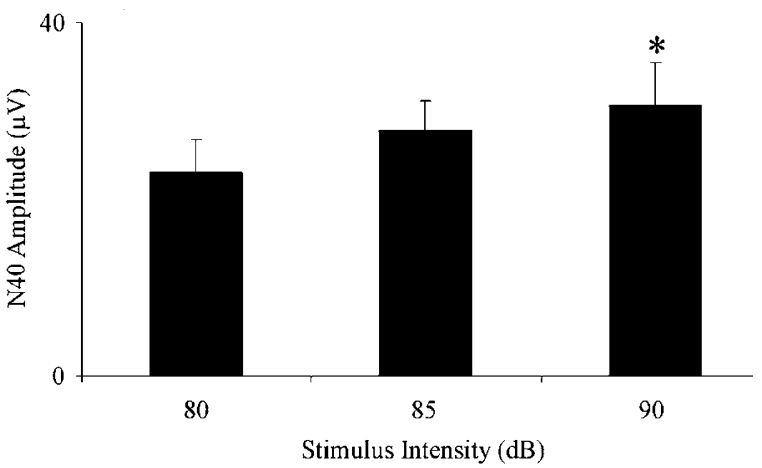

Figure 2 Mean \pm SEM for the N40 stimulus intensity response. Fisher $\mathrm{LSD}$ post hoc $M S=510, \mathrm{df}=78 ; 80$ vs $85 \mathrm{db}, p=0.067 ; 80$ vs $90 \mathrm{db}$, $p=0.002 ; 85$ vs $90 \mathrm{db}, p=0.208$.

\section{RESULTS}

\section{AEP}

A main effect of corticosterone dose indicated that $\mathrm{N} 40$ amplitude varied according to the dose of corticosterone administered $(\mathrm{F}(4,39)=3.5, p=0.014)$. A main effect of stimulus intensity showed that the N40 amplitude increased with increasing stimulus intensity $(\mathrm{F}(2,78)=5.1, p=0.009)$ (Figure 2). Consistent with previous data, a main effect of ISI demonstrated increased amplitude with increasing ISI between 0.25 and $8 \mathrm{~s}(\mathrm{~F}(3,117)=18.2, p<0.001)$ (Maxwell et al, 2004b).

The interaction between corticosterone treatment and ISI described below indicates that the effects of corticosterone on N40 amplitude vary across ISIs $(\mathrm{F}(12,117)=2.2$, $p=0.015)$, suggesting that the dose of corticosterone modulated the auditory recovery cycle (gating). Post hoc analyses of this interaction indicated that the $1 \mathrm{mg} / \mathrm{kg} / \mathrm{day}$ dose did not produce any changes in gating relative to vehicle. However, the $5 \mathrm{mg} / \mathrm{kg} / \mathrm{day}$ dose enhanced gating and the 15 and $30 \mathrm{mg} / \mathrm{kg} /$ day doses both diminished gating relative to the control (vehicle) condition. The decrease in auditory gating with high-dose corticosterone was driven by a reduction in amplitude at the long ISIs (8 and $4 \mathrm{~s}$ ) (Figure 3). No interactions were found between corticosterone dose and stimulus intensity, suggesting that corticosterone dose does not modulate auditory sensitivity $(\mathrm{F}(8,78)=0.7, p=0.707)$. Additionally, there was no significant three-way interaction between corticosterone dose, stimulus intensity, and ISI $(\mathrm{F}(24,234)=0.9$, $p=0.582$ ).

\section{Serum Corticosterone}

There were main effects of corticosterone dose on N40 amplitude (AEP results: $p=0.014$ ) and serum corticosterone concentration $(\mathrm{F}(4,35)=2.7, p=0.043)$. A correlation analysis between N40 amplitude and serum corticosterone levels revealed a significant negative correlation in which decreased N40 amplitudes at the $8 \mathrm{~s}$ ISI were associated with elevated serum corticosterone levels $(r=-0.370, p=0.019)$ (Figure 4). No correlation was found at any other ISI ( $4 \mathrm{~s}$, $p=0.764 ; 0.5 \mathrm{~s}, p=0.612$; and $0.25 \mathrm{~s}, p=0.689$ ).

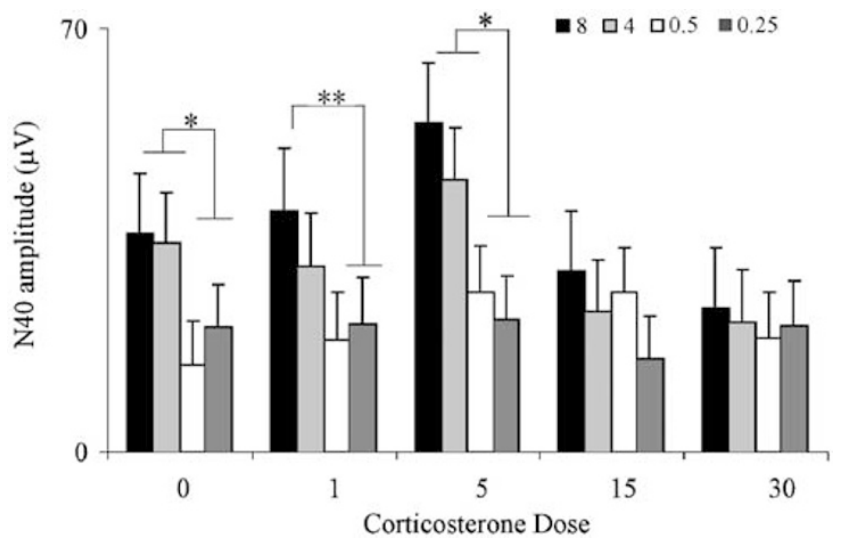

Figure 3 Mean \pm SEM for the corticosterone by ISI interaction $(\mu \mathrm{V})$ in which * indicates that the individual long ISI amplitudes are significantly different from each short ISI amplitudes, $p<0.05$; ** indicates that the $8 \mathrm{~s}$ ISI differs from both 0.5 and $0.25 \mathrm{~s}$ ISI. Fisher LSD post hoc analysis for the individual differences between long ( 8 and $4 \mathrm{~s})$ and short ( 0.5 and $0.25 \mathrm{~s}$ ) ISI within each condition (MS $=206, \mathrm{df}=133$ ) are below. Vehicle: $p<0.01$ for 8 vs 0.5 (effect size: -0.7316 ) and 4 vs 0.5 (effect size: -0.7989 ); $p<0.03$ for 8 vs 0.25 (effect size: -0.5 I89) and 4 vs 0.25 (effect size: -0.5476 ); I mg/kg/day: $p<0.0$ l for 8 vs 0.5 (effect size: -0.7070 ) and 8 vs 0.25 (effect size: -0.6239 ); $p>0.05$ for 4 vs 0.5 (effect size: -0.4745 ) and 4 vs 0.25 (effect size: -0.3763 ); $5 \mathrm{mg} / \mathrm{kg} / \mathrm{day}: p<0.02$ for 8 vs 0.5 (effect size: -0.9352 ), 8 vs 0.25 (effect size: -1.0889 ), 4 vs 0.5 (effect size: -0.7409 ), and 4 vs 0.25 (effect size: -0.9224 ); $15 \mathrm{mg} / \mathrm{kg} / \mathrm{day}: p<0.02$ for 8 vs 0.25 (effect size: -0.4788 ); $p>0.05$ for 8 vs 0.5 (effect size: -0.1 I I 8 ), 4 vs 0.5 (effect size: 0.1236 ), and 4 vs 0.25 (effect size: -0.2624 ); $30 \mathrm{mg} / \mathrm{kg} / \mathrm{day}$ : $p>0.05$ for 8 vs 0.5 (effect size: -0.1603 ), 8 vs 0.25 (effect size: -0.09 I 8 ), 4 vs 0.5 (effect size: -0.1037 ), and 4 vs 0.25 (effect size: -0.0227 ).

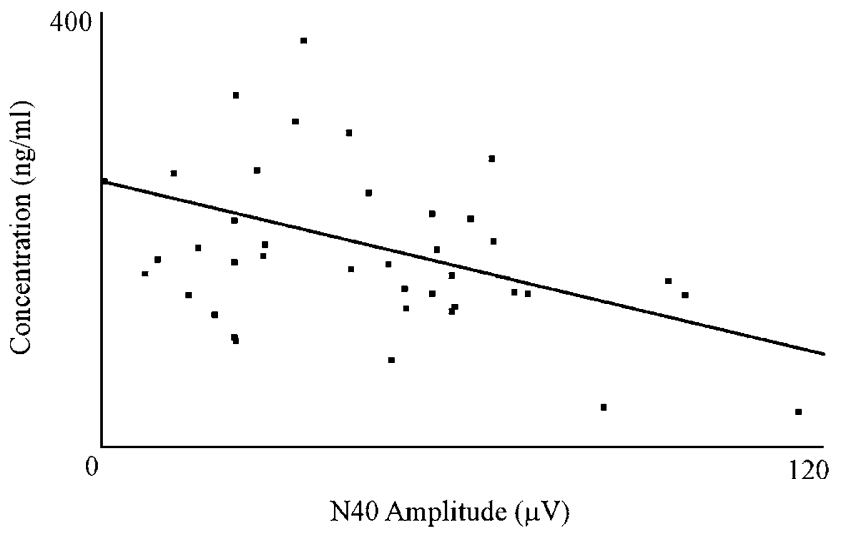

Figure 4 Negative correlation between serum corticosterone concentration $(\mathrm{ng} / \mathrm{ml})$ and $\mathrm{N} 40$ amplitude $(\mu \mathrm{V})$ at the $8 \mathrm{~s}$ ISI $(r=-0.370$, $p=0.019)$. Squares indicate data for individual mice.

\section{DISCUSSION}

The current study assessed the effects of serum glucocorticoid levels on auditory stimulus processing in C57BL/6 mice. Our results indicate that corticosterone modulates the recovery cycle (gating), but not the intensity function of evoked potentials. This effect on auditory gating occurs primarily by influencing the amplitude of response at long ISI. Our evaluation of AEP in mice treated with different doses of corticosterone for 14 days suggests that $5 \mathrm{mg} / \mathrm{kg} /$ day of corticosterone enhanced gating, whereas 15 
and $30 \mathrm{mg} / \mathrm{kg} /$ day impaired gating through decreased N40 amplitude at long ISI. Importantly, the inverted U-shaped N40 dose-response to corticosterone demonstrates a limited range of doses that are sensitive to psychometric alterations. Examination of circulating corticosterone levels revealed a negative correlation between $\mathrm{N} 40$ amplitude at the $8 \mathrm{~s}$ ISI and serum corticosterone levels in which increased circulating corticosterone were associated with decreased N40 amplitude. Again, this produces a U-shaped doseresponse that is consistent with the N40 data. Based on these data, we propose that circulating glucocorticoids influence generation of auditory response (amplitude) and auditory gating (ISI) but not auditory threshold (stimulus intensity). These data provide further evidence that peripheral corticosterone levels can alter auditory processing and have implications for schizophrenia and depression. Additionally, glucocorticoid-induced alterations in auditory processing may have relevance for steroid-induced psychosis, which can be associated with auditory hallucinations and may provide additional clinical relevance for the data within this study (Hall et al, 1979).

Patients with schizophrenia display alterations in response to auditory stimuli as measured by AEP. One study indicated that schizophrenic patients display deficits in response to long but not short ISI (Shelley et al, 1999). This endophenotype is thought to reflect a fundamental disruption in information processing that is related to the disease state. Our results demonstrating that high-dose chronic corticosterone suppresses responses to long ISI suggests a broader mechanism by which the AEP recovery cycle may be disrupted in a variety of medical and psychiatric illnesses. These data provide a foundation for studying glucocorticoid modulation in a variety of disorders where sensory processing is impaired. However, patterns of AEP abnormalities differ among various psychiatric diagnoses. For example, patients with schizophrenia display decreased amplitudes of the P50 and N100 as well as P200 amplitudes that vary with task and state (Boutros et al, 1997; Jin et al, 1997; Ogura et al, 1991; Tabares-Seisdedos et al, 2001). In contrast to schizophrenia, patients with major depression display normal N100 amplitude and increased P200 amplitude (Vandoolaeghe et al, 1998). In schizophrenia, unmedicated patients have $37 \%$ higher cortisol levels compared to controls, and similarly, depressed patients have $28 \%$ higher cortisol levels relative to controls (MuckSeler et al, 2004). Therefore, as hypercortisolemia may be associated with schizophrenia and major depression, our data highlight the importance of controlling for glucocorticoid milieu when assessing disease-related alterations in auditory processing.

Our data also assessed the stimulus intensity response properties of the mouse N40. These data suggest that the mouse N40 increases in amplitude with increased stimulus intensity. The human N100 also displays a similar pattern of augmentation with increasing stimulus intensity (Halford, 2003; Hegerl et al, 2001). Conversely, the human P50 displays suppression with increasing stimulus intensity (Ninomiya et al, 2000). Therefore, these data taken together with previous reports support the hypothesis that the mouse N40 shares multiple psychometric and pharmacological response properties with the human N100, which is thought to be cortically generated (Maxwell et al, 2004a, b;
Umbricht et al, 2004). However, other studies have linked the rodent P20-N40 difference complex to the human P50 based on latency, gating, and pharmacological similarities (Siegel et al, 2005; Stevens et al, 1999). Although the analogy between the mouse N40 and the corresponding human AEP component is uncertain, we propose that the human P50 and/or N100 may be modulated by glucocorticoid milieu in a manner similar to the mouse N40 in the present study.

One limitation of the current study results from a lack of serial glucocorticoid assessments at various times of day within each animal. We chose not to assess diurnal variation in these animals in order to minimize the stress associated with repeated retro-orbital serum sampling. Although information regarding the effects of exogenous corticosterone on diurnal variation in glucocorticoid concentration is an important consideration, the stress associated with the required procedures would likely have confounded interpretation of the relationship between the pharmacological manipulation and primary electrophysiological outcome measure. Additionally, we did not evaluate other neurochemical or neuroendocrine factors of the stress response cascade including but not limited to corticotrophin releasing factor and adrenocorticotrophic hormone as well as central glucocorticoid or mineralocorticoid receptor systems and peripheral endocrine responsive organs, which have been extensively mapped in human and rodent studies as well as in disease states (Arborelius et al, 2000; Miller et al, 1990; Nemeroff, 2004). We believe that influences from the aforementioned factors may help provide insight into the mechanisms by which chronic glucocorticoid treatment modulates AEP and that these factors should be addressed in future studies.

An additional consideration in interpreting the implications of this report is that C57BL/6 mice may be highly susceptible to manipulations that involve steroid or hormonal modulation relative to other inbred strains. For example, this strain has been shown to exhibit increased vulnerability to a metabolic disorder induced by the enzyme 11-beta-hydrosteroid-dehydrogenase (11beta-HSD-1) in adipose tissue while fed a high-fat diet (Morton et al, 2004). Increased vulnerability to disorders of metabolism is thought to reflect reduced downregulation of 11 beta-HSD-1, which leads to a persistent amplification of intracellular glucocorticoid signal transduction (Morton et al, 2004). Additionally, 11beta-HSD-1 has been proposed to mediate glucocorticoid effects within the central nervous system, where it is selectively expressed in the cerebellum, hippocampus, cortex, and pituitary, with low levels also in the hypothalamus (Seckl, 1997). Therefore, C57BL/6 mice may represent an extreme of glucocorticoid sensitivity for electrophysiological changes as well as dietary manipulation. As such, this study may have implication for the role of intracellular signal transduction of the glucocorticoid pathway in a variety of disease states.

To summarize, our findings demonstrate serum corticosterone concentration is negatively correlated with N40 amplitude in C57BL/6J mice. Additionally, high-dose chronic corticosterone produces a reduction in N40 gating, which we propose may have relevance to the mechanisms of reduced N100 recovery cycle in schizophrenia. We further suggest that our observations may be particularly relevant to schizophrenia by reproducing the reduction in amplitude 
of evoked potentials at long ISIs. These data also highlight the need for assessing circulating glucocorticoids when measuring evoked potentials in any human disease trait or state. Thus, we propose that glucocorticoid milieu may influence auditory processing and modulate the human P50 and/or N100 across a variety of medical and psychiatric disorders that impinge on the stress cascade.

\section{ACKNOWLEDGEMENTS}

This work was supported by Eli Lilly and Co. (SJS), P50 MH 6404501 (SJS, TA, SJK) and The Stanley Medical Research Institute (SJS). We thank Dr Irwin Lucki, Dr Rita Valentino, Dr Karen Stevens, and Dr Raquel Gur for helpful comments and discussions during the formulation of this manuscript.

\section{REFERENCES}

Adler LE, Rose G, Freedman R (1986). Neurophysiological studies of sensory gating in rats: effects of amphetamine, phencyclidine, and haloperidol. Biol Psychiatry 21: 787-798.

Arborelius L, Skelton KH, Thrivikraman KV, Plotsky PM, Schulz DW, Owens MJ (2000). Chronic administration of the selective corticotropin-releasing factor 1 receptor antagonist CP-154,526: behavioral, endocrine and neurochemical effects in the rat. J Pharmacol Exp Ther 294: 588-597.

Ashton CH, Lunn B, Marsh VR, Young AH (2000). Subchronic hydrocortisone treatment alters auditory evoked potentials in normal subjects. Psychopharmacology (Berl) 152: 87-92.

Born J, Hitzler V, Pietrowsky R, Pauschinger P, Fehm HL (1989). Influences of cortisol on auditory evoked potentials (AEPs) and mood in humans. Neuropsychobiology 20: 145-151.

Boutros N, Nasrallah H, Leighty R, Torello M, Tueting P, Olson S (1997). Auditory evoked potentials, clinical $v s$ research applications. Psychiatry Res 69: 183-195.

Budd TW, Barry RJ, Gordon E, Rennie C, Michie PT (1998). Decrement of the N1 auditory event-related potential with stimulus repetition: habituation $v s$ refractoriness. Int J Psychophysiol 31: 51-68.

Connolly PM, Maxwell C, Liang Y, Kahn JB, Kanes SJ, Abel T et al (2004). The effects of ketamine vary among inbred mouse strains and mimic schizophrenia for the P80, but not P20 or N40 auditory ERP components. Neurochem Res 29: 1179-1188.

Connolly PM, Maxwell CR, Kanes SJ, Abel T, Liang Y, Tokarczyk J et al (2003). Inhibition of auditory evoked potentials and prepulse inhibition of startle in DBA/2J and DBA/2Hsd inbred mouse substrains. Brain Res 992: 85-95.

DeKrey GK, Kerkvliet NI (1995). Effects of exogenous corticosterone treatment on alloantigen-specific cytotoxic $\mathrm{T}$ lymphocyte activity in mice. J Pharmacol Exp Ther 273: 823-829.

Ehlers CL, Somes C (2002). Long latency event-related potentials in mice: effects of stimulus characteristics and strain. Brain Res 957: 117-128.

Erway LC, Willott JF, Archer JR, Harrison DE (1993). Genetics of age-related hearing loss in mice: I. Inbred and F1 hybrid strains. Hear Res 65: 125-132.

Erwin RJ, Shtasel D, Gur RE (1994). Effects of medication history on midlatency auditory evoked responses in schizophrenia. Schizophr Res 11: 251-258.

Frankel WN, Beyer B, Maxwell CR, Pretel S, Letts VA, Siegel SJ (2005). Development of a new genetic model for absence epilepsy: spike-wave seizures in $\mathrm{C} 3 \mathrm{H} / \mathrm{He}$ and backcross mice. J Neurosci 25: 3452-3458.

Glass GV, McGaw B, Smith ML (1981). Meta-Analysis in Social Research. Sage: Newbury Park, CA.
Halford JJ (2003). Neurophysiologic correlates of psychiatric disorders and potential applications in epilepsy. Epilepsy Behav 4: 375-385.

Hall RC, Popkin MK, Stickney SK, Gardner ER (1979). Presentation of the steroid psychoses. J Nerv Ment Dis 167: 229-236.

Hegerl U, Gallinat J, Juckel G (2001). Event-related potentials. Do they reflect central serotonergic neurotransmission and do they predict clinical response to serotonin agonists? J Affect Disord 62: 93-100.

Janowsky DS, Risch C (1979). Amphetamine psychosis and psychotic symptoms. Psychopharmacology (Berl) 65: 73-77.

Javitt DC, Jayachandra M, Lindsley RW, Specht CM, Schroeder CE (2000). Schizophrenia-like deficits in auditory P1 and N1 refractoriness induced by the psychomimetic agent phencyclidine (PCP). Clin Neurophysiol 111: 833-836.

Jin Y, Potkin SG, Patterson JV, Sandman CA, Hetrick WP, Bunney Jr WE (1997). Effects of P50 temporal variability on sensory gating in schizophrenia. Psychiatry Res 70: 71-81.

Knight RT, Brailowsky S, Scabini D, Simpson GV (1985). Surface auditory evoked potentials in the unrestrained rat: component definition. Electroencephalogr Clin Neurophysiol 61: 430-439.

LaBossiere E, Glickstein M (1976). Histological Processing for the Neural Science. Charles C Thomas: Springfield.

Liang Y, Trief D, Maxwell CR, Majumdar SM, Majewski-Tiedeken C, Kanes SJ et al (2004). Inbred Strains Vary for Effects of Acute Ketamine. Society for Neuroscience: Washington, DC.

Light GA, Braff DL (1999). Human and animal studies of schizophrenia-related gating deficits. Curr Psychiatry Rep 1: 31-40.

Man MS, Young AH, McAllister-Williams RH (2002). Corticosterone modulation of somatodendritic 5-HT1A receptor function in mice. J Psychopharmacol 16: 245-252.

Maxwell CR, Kanes SJ, Abel T, Siegel SJ (2004a). Phosphodiesterase inhibitors: a novel mechanism for receptor-independent antipsychotic medications. Neuroscience 129: 101-107.

Maxwell CR, Liang Y, Weightman BD, Kanes SJ, Abel T, Gur RE et al (2004b). Effects of chronic olanzapine and haloperidol differ on the mouse N1 auditory evoked potential. Neuropsychopharmacology 29: 739-746.

McAllister-Williams RH, Rugg MD (2002). Effects of repeated cortisol administration on brain potential correlates of episodic memory retrieval. Psychopharmacology (Berl) 160: 74-83.

Miller AH, Spencer RL, Stein M, McEwen BS (1990). Adrenal steroid receptor binding in spleen and thymus after stress or dexamethasone. Am J Physiol 259: E405-12.

Morton NM, Ramage L, Seckl JR (2004). Down-regulation of adipose 11beta-hydroxysteroid dehydrogenase type 1 by high-fat feeding in mice: a potential adaptive mechanism counteracting metabolic disease. Endocrinology 145: 2707-2712.

Muck-Seler D, Pivac N, Mustapic M, Crncevic Z, Jakovljevic M, Sagud M (2004). Platelet serotonin and plasma prolactin and cortisol in healthy, depressed and schizophrenic women. Psychiatry Res 127: 217-226.

Nemeroff C (2004). Early-life adversity, CRF dysregulation, and vulnerability to mood and anxiety disorders. Psychopharmacol Bull 38: 14-20.

Ninomiya H, Sato E, Onitsuka T, Hayashida T, Tashiro N (2000). Auditory P50 obtained with a repetitive stimulus paradigm shows suppression to high-intensity tones. Psychiatry Clin Neurosci 54: 493-497.

Ogura C, Nageishi Y, Matsubayashi M, Omura F, Kishimoto A, Shimokochi M (1991). Abnormalities in event-related potentials, N100, P200, P300 and slow wave in schizophrenia. Jpn J Psychiatry Neurol 45: 57-65.

Pincze Z, Lakatos P, Rajkai C, Ulbert I, Karmos G (2001). Separation of mismatch negativity and the N1 wave in the auditory cortex of the cat: a topographic study. Clin Neurophysiol 112: 778-784.

Seckl JR (1997). 11beta-hydroxysteroid dehydrogenase in the brain: a novel regulator of glucocorticoid action? Front Neuroendocrinol 18: 49-99. 
Shelley AM, Silipo G, Javitt DC (1999). Diminished responsiveness of ERPs in schizophrenic subjects to changes in auditory stimulation parameters: implications for theories of cortical dysfunction. Schizophr Res 37: 65-79.

Siegel SJ, Connolly P, Liang Y, Lenox RH, Gur RE, Bilker WB et al (2003). Effects of strain, novelty, and NMDA blockade on auditory-evoked potentials in mice. Neuropsychopharmacology 28: 675-682.

Siegel SJ, Maxwell CR, Majumdar S, Trief DF, Lerman C, Gur RE et al (2005). Monoamine reuptake inhibition and nicotine receptor antagonism reduce amplitude and gating of auditory evoked potentials. Neuroscience 133: 729-738.

Siegel SJ, Winey KI, Gur RE, Lenox RH, Bilker WB, Ikeda D et al (2002). Surgically implantable long-term antipsychotic delivery systems for the treatment of schizophrenia. Neuropsychopharmacology 26: 817-823.

Stevens KE, Bullock AE, Collins AC (2001). Chronic corticosterone treatment alters sensory gating in $\mathrm{C} 3 \mathrm{H}$ mice. Pharmacol Biochem Behav 69: 359-366.

Stevens KE, Kem WR, Freedman R (1999). Selective alpha 7 nicotinic receptor stimulation normalizes chronic cocaine- induced loss of hippocampal sensory inhibition in $\mathrm{C} 3 \mathrm{H}$ mice. Biol Psychiatry 46: 1443-1450.

Tabares-Seisdedos R, Balanza-Martinez V, Pallardo Y, Salazar-Fraile J, Selva G, Vilela C et al (2001). Similar effect of family history of psychosis on Sylvian fissure size and auditory P200 amplitude in schizophrenic and bipolar subjects. Psychiatry Res 108: 29-38.

Umbricht D, Vyssotky D, Latanov A, Nitsch R, Brambilla R, D'Adamo $\mathrm{P}$ et al (2004). Midlatency auditory event-related potentials in mice: comparison to midlatency auditory ERPs in humans. Brain Res 1019: 189-200.

Vandoolaeghe E, van Hunsel F, Nuyten D, Maes M (1998). Auditory event related potentials in major depression: prolonged P300 latency and increased P200 amplitude. J Affect Disord 48: 105-113.

Willott JF, Carlson S (1995). Modification of the acoustic startle response in hearing-impaired C57BL/6J mice: prepulse augmentation and prolongation of prepulse inhibition. Behav Neurosci 109: 396-403.

Zheng QY, Johnson KR, Erway LC (1999). Assessment of hearing in 80 inbred strains of mice by ABR threshold analyses. Hear Res 130: $94-107$. 